\title{
A ADMINISTRAÇÃO BUROCRÁTICA E SUA REPERCUSSÃO NA GESTÃO ESCOLAR
}

\author{
A. M. B. N. TAVARES ${ }^{1}$, M. A. AZEVEDO e P. S. MORAIS \\ Instituto Federal de Educação, Ciência e Tecnologia do Rio Grande do Norte \\ andrezza.tavares@ifrn.edu.br ${ }^{1}$
}

Artigo submetido em fevereiro/2014 e aceito em março/2014

\begin{abstract}
RESUMO
Neste trabalho tem-se o objetivo de analisar as modificações na organização da administração pública e suas repercussões na política educacional e na gestão da escola a partir dos anos de 1930. Vale salientar que o burocrático se desenvolveu no início do século XX para combater a corrupção e o nepotismo/clientelismo herdados do modelo anterior (o patrimonialista), tendo sua origem relacionada à célula do Estado moderno Ocidental. Como fundamentação teórico-metodológica utilizou-se estudo de literatura especifica sobre a
\end{abstract}

organização do modelo burocrático e seu impacto na gestão da escola pública. Na pesquisa pode-se perceber que os mecanismos de divisão do trabalho da iniciativa privada orientaram as ações da gestão da educação e da escola, em que os sujeitos e o ensino são orientados pela lógica burocrática baseado em procedimentos rígidos por meio do controle dos processos de trabalho, interferindo inclusive na organização da escola ou mesmo no próprio relacionamento interpessoal entre professor e aluno.

PALAVRAS-CHAVE: Modelo burocrático; gestão escolar; política educacional.

\section{BUREAUCRATIC AND ITS IMPACT ON SCHOOL MANAGEMENT}

\begin{abstract}
This work has the objective of analyzing the changes in the organization of the public administration and its impact on educational policy and school management since the 1930s. It is worth mentioning that the bureaucratic developed in the early twentieth century to fight the corruption and nepotism/patronage inherited from the previous model (the patrimonial), having its origin related to the modern Western state cell. As theoretical-methodological base, it has been used the study of the specific literature on the organization of the
\end{abstract}

bureaucratic model and its impact on the public schools management. In the research, it can be seen that the mechanisms of labor division in private sector guided the actions of education and school management, in which the subjects and the teaching are driven by the bureaucratic logic based on rigid procedures through control of work processes, even interfering in the organization of the school or in interpersonal relationship between teacher and student.

KEYWORDS: Bureaucratic model; school management; educational policy. 


\title{
1 INTRODUÇÃO
}

No momento é imprescindível compreender as origens da organização burocrática como forma de organização humana apresentando-se como estratégia de administração e dominação. Conforme Motta e Pereira (1984) a origem da organização burocrática remonta-se à época da Antiguidade, melhor dizendo, nas formações pré-capitalistas, período em que o ser humano elaborou e registrou seus primeiros códigos de normatização das relações entre o Estado e as pessoas e destas entre si. No entanto, o modelo de burocracia presente nas sociedades modernas teve sua ascendência nas mudanças religiosas verificadas após o Renascimento. Vale salientar, que ao longo dos anos a burocracia caracterizou-se como uma organização e/ou sistema de dominação ou de poder autoritário e hierárquico, baseando-se na racionalidade e no conhecimento administrativo.

\section{ORIGENS DO MODELO BUROCRÁTICO E SUAS REPERCUSSÕES NA ADMINISTRAÇÃO PÚBLICA}

As organizações burocráticas ${ }^{1}$ desde sua origem retratam a reprodução do conjunto das relações sociais determinadas pelo sistema econômico dominante. Desse modo, a burocracia caracterizou-se como uma forma de organização humana que se baseou na racionalidade, na adequação dos meios às finalidades pretendidas, a fim de garantir a máxima eficiência possível no alcance dos objetivos. No entanto, vale salientar que o aparecimento e a predominância das organizações industriais modernas, em meados do século $\mathrm{XX}$, desencadearam o processo do capitalismo industrial. Além do mais, é imprescindível destacar a materialização do Estado capitalista que intensificou as possibilidades de concretização da burocracia em diversos corpos sociais seja público ou privado. Esse Estado deve atuar sobre os corpos sociais de modo a tornálos fragmentados, homogêneos em sua divisão e promover uniformidade no isolamento de seus elementos para a concretização das decisões emanadas. De acordo com Poulantzas (2000, p. 6061):

\begin{abstract}
Esse Estado supõe necessariamente uma organização particular do espaço político sobre o qual exerce o poder. Estado (centralizado, burocratizado e etc.) instaura essa otimização e representa (Estado representativo) a unidade do corpo (povonação), fracionando-o em mônadas formalmente equivalentes (soberania nacional, vontade popular).
\end{abstract}

\footnotetext{
${ }^{1}$ Cruz (2006, p. 03) descreve a origem da organização formal burocrática: "Seu surgimento se deu como forma de dominação estatal na antiga Mesopotâmia, Índia, Rússia, China e antigo Egito. Emergindo como mediação dos interesses particulares e gerais, pode ser caracterizada no modo de produção asiático, coordenando os esforços da sociedade, determinando maior divisão de trabalho, separando mais rigidamente a agricultura e o artesanato. Dá-se, então, a apropriação de poucos representantes da sociedade. No Egito, na antiga Mesopotâmia e na China, a água era controlada por funcionários do Estado que exerciam dominação sobre os camponeses, que eram incapazes de se organizarem. Sua ideologia se mostra na divisão dos funcionários como portadores de símbolos, e não pelo conhecimento técnico e utilitário real". Percebe-se que a organização burocrática desde sua origem centraliza suas preocupações no total controle do processo de trabalho, sendo a rigidez umas das marcas imponentes do modo de produção.
} 
O Estado configurado no período pós-guerra destaca-se por ser centralizador e burocratizado. A Alemanha e a Inglaterra neste período vivenciaram a implementação de Estado centralizador e burocrático, despontaram nos mercados mundiais ao absorverem as diretrizes do universo capitalista. Essas transformações promoveram o desenvolvimento de diversos estudos na área das ciências sociais. Dentre eles, podemos destacar o sociólogo alemão Marx Weber que procurou estudar as características gerais das organizações burocráticas. Para a compreensão da teoria burocrática é necessário analisar as características contextuais que a tornaram um sistema dominante nas organizações. Segundo Cruz (2006, p. 04):

\begin{abstract}
A burocracia surgiu em função de alguns aspectos, como a necessidade de métodos teóricos que possibilitassem uma abordagem global e integrada dos problemas organizacionais - tentativa que Taylor e Fayol exploraram em suas teorias, porém, com enfoques totalmente divergentes e incompletos, que se caracterizam, na maioria das variáveis, como a organização estrutural e do comportamento humano - da tendência de crescimento das organizações, que necessitariam de modelos bem definidos e aplicados a grandes estruturas, e do descobrimento das obras de Weber, que rapidamente foram aplicadas de forma prática, proporcionando as bases para a Teoria da Burocracia.
\end{abstract}

No intuito de conhecer as características da teoria burocrática se faz necessário evidenciar o ideário weberiano. Weber (1991) destaca a relevância da burocracia moderna para a administração pública e apresenta como possibilidade de sucesso para a administração burocrática a utilização da racionalidade. Melhor dizendo, a administração burocrática significa a efetivação da dominação por meio do conhecimento racional. Weber (1991, p. 147) esclarece que a dominação burocrática significa:

1) a tendência ao nivelamento no interesse da possibilidade de recrutamento universal a partir dos profissionalmente mais qualificados;

2) a tendência à plutocratização no interesse de um processo muito extenso de qualificação profissional (frequentemente quase até o fim da terceira década da vida);

3) a dominação da impessoalidade formalista: sine ira et studio, sem ódio e paixão, e, portanto, sem "amor" e "entusiasmo", sob a pressão de simples conceitos de dever, sem considerações pessoais, de modo formalmente igual para "cada qual", isto é, cada qual dos interessados que efetivamente se encontram em situação igual - é assim que o funcionário ideal exerce seu cargo.

Nesse sentido, a racionalidade administrativa deve orientar as ações dos que exercem os cargos. As normas e regulamentos organizam as tarefas exercidas na administração burocrática. Os funcionários concentram suas ações no controle e na garantia da permanência do poder do Estado. Permitem que a administração burocrática atinja o grau máximo de rigor e formalismo ao definirem suas tarefas por meio de registros não permitindo, assim, possibilidades de desvios ou possíveis equívocos no desenvolvimento das atividades administrativas. Segundo Weber (1991, p. 145): 
A administração puramente burocrática, portanto, a administração burocráticomonocromática mediante documentação, considera do ponto de vista formal, é, segundo toda a experiência, a forma mais radical de exercício da dominação, porque nela se alcança tecnicamente o máximo de rendimento em virtude de precisão, continuidade, disciplina, rigor e confiabilidade - isto é, calculabilidade tanto para o senhor quanto para os demais interessados -, intensidade e extensibilidade dos serviços, e aplicabilidade formalmente universal a todas as espécies de tarefas.

A dimensão conceitual de burocracia que possui maior repercussão é a proposição clássica de Weber, concebendo a burocracia como uma forma de dominação racional-legal. Vale salientar, que ele considera a burocracia como o padrão mais eficiente da administração. Tragtenberg (1980, p. 139) interpretando o pensamento de Weber afirma: "A burocracia para ele é um tipo de poder. Burocracia é igual à organização. É um sistema racional em que a divisão de trabalho se dá racionalmente com vista a fins. A ação racional burocrática é a coerência da relação de meios e fins visados". Esse conceito considera a burocracia como dominação, sendo cada vez mais próxima dos fenômenos necessários tradicionalmente nas organizações públicas. Cabe enfatizar que o principal modelo referente aos estudos e pesquisas neste campo de conhecimento é dado pela análise do tipo ideal propugnado por Max Weber. Nessa perspectiva, Matos $(1979$, p. 22) analisa a ênfase dada por Weber a concepção burocrática como sendo a mais completa na teoria da administração.

\begin{abstract}
Max Weber, sociólogo alemão, o maior teórico da burocracia liga o conceito de burocratização às exigências decorrentes da grande dimensão atingida pela estrutura organizacional e a grande complexidade que caracteriza suas responsabilidades. Para justificar a superioridade da burocracia, sobretudo as formas historicamente conhecidas de administração, Weber alinhou fatores tais como: estabilidade, previsibilidade de resultados e magnitude e controle das operações.
\end{abstract}

Nesse sentido, pode-se dizer que o tipo ideal weberiano se tornou a principal fonte inspiradora da maioria dos estudos no que concerne a organização administrativa, sobretudo, após a II Grande Guerra Mundial. Estabelece-se de acordo com concepções do modelo weberiano o modelo de gestão burocrático, com algumas características, dentre as quais se pode destacar: atividades conduzidas por normas escritas, formalismo, divisão do trabalho horizontal e vertical, cargos estabelecidos de forma hierarquizantes, regras e normas técnicas para desempenho de cada cargo, seleção de pessoal realizada por meio do mérito, impessoalidade, separação entre propriedade e administração (TRAGTENBERG, 1980).

No plano administrativo a gestão pública em desenvolvimento após a II guerra mundial baseava-se no modelo burocrático de administração, embasado na teoria weberiana, uma vez que o denominado modelo burocrático weberiano pautava-se em princípios como a impessoalidade, neutralidade e racionalidade do poder governamental (ABRUCIO, 1998). Tal modelo conduzia a formulação de um aparato administrativo estatal que primava por processo rígido (sistemas de normas e regulamentos), desenvolvido por pessoal altamente especializado, que ocupa cargos organizados por meio de hierarquização expressando limites de autoridade previamente definidos. De um modo geral, a teoria burocrática possui características essenciais que tem como foco o processo administrativo e a efetivação de resultados. Dessa forma, é necessário intensificar as 
características do modelo burocrático. Pereira (2003, p. 28) de maneira sintética destaca as características do modelo burocrático na realidade brasileira:

A burocracia atenta para os processos, sem considerar a alta ineficiência envolvida, por que acredita que este seja o modo mais seguro de evitar o nepotismo e a corrupção. Os controles são preventivos, vêm a priori. Entende, além disso, que punir os desvios é sempre difícil, para não dizer impossível; prefere, pois, prevenir. A rigor, uma vez que sua ação não tem objetivos claros definir indicadores de desempenho para as agências estatais é tarefa extremamente difícil -, não tem alternativa senão controlar os procedimentos.

Em sua essência, a administração burocrática tem características que, na ocasião, atendiam aos anseios imediatos necessários ao controle das ações da gestão pública. A impessoalidade passou a ser essencialmente exercida com o intuito de impor a hierarquização dos cargos, auxiliando ao controle e ao formalismo dos procedimentos administrativos. Desse modo, a impessoalidade merece destaque, uma vez que permite aos possuidores dos cargos não considerar as pessoas, mas desenvolver suas funções com o intuito de sustentar e aperfeiçoar a eficiência administrativa. Para Castro (2007, p. 120), os:

[...] administradores do modelo burocrático devem ser profissionais e, antes de tudo, especialistas: homens especialmente treinados para exercer diversas funções criadas pela divisão do trabalho, os quais geralmente devem ter um diploma e/ou experiência para poder ocupar um cargo.

Assim, pode-se perceber que o administrador burocrático não domina ou mesmo acompanha os meios de produção, mas apenas exerce sem desvios suas funções, administrando em nome de terceiros com fidelidade ao cargo. No interior do modelo burocrático, o administrador é um especialista intensamente treinado para alcançar a eficiência administrativa. Deve agir de modo a evitar os erros e refutar envolvimento afetivo. Tragtenberg (1980, p. 139) considerando o pensamento de Weber descreve a relação profissional entre os que possuem cargos e o meio de produção:

[...] a administração burocrática para Weber apresenta como notas dominantes a especialização, o fato de constituir-se em profissão e não em honraria; a separação do administrador dos meios de administração, a fidelidade impessoal ao cargo, a remuneração em dinheiro. A nomeação do burocrata é sempre feita por autoridade superior a ele, e sua atividade constitui carreira que finda com sua aposentadoria do serviço.

A impessoalidade formalista utilizada pelo administrador é orientada por normas registradas e racionais que determinam de forma precisa as relações de mando e obediência para conduzir as ações ao fim almejado. A hierarquização é o modelo que define os cargos por meio de uma administração intensamente planejada e organizada. Por consequência, existe uma definição rígida de autoridade vertical (com competências funcionais fixas) e uma divisão do trabalho horizontal de maneira que o processo de departamentalização seja claramente percebido. As ações empenhadas pelo administrador devem ter, apenas como foco a execução utilitarista de suas tarefas administrativas. Diante disso, o administrador burocrático deve desempenhar seu cargo por meio do controle dos processos administrativos para que ocorra a efetivação do poder exercido e o consequente sucesso da ação administrativa planejada. 


\section{O MODELO BUROCRÁTICO E SUAS REPERCUSSÕES NA ORGANIZAÇÃO ESCOLAR}

A organização burocrática chega à escola brasileira interferindo em sua gestão como um todo alcançando o nível administrativo e pedagógico, bem como sua relação com a sociedade. A imposição de funções próximas das instituídas nas empresas capitalista marca a administração escolar, particularmente a partir dos anos de 1930, no contexto do Estado Novo. Sander (2007, p. 27-28) contextualiza a predominância da fase organizacional na administração da educação brasileira, em que a ênfase aos regulamentos para o controle organização da educação brasileira:

A efervescência política e intelectual que marcou o começo do século XX - desde a I Guerra Mundial até a Revolução de 1930, passando pela Grande Depressão no final da década de 1920 - manifestou-se também no setor público e na educação, dando início a numerosos movimentos reformistas na administração do Estado e na gestão da educação. No campo da educação, essa efervescência intelectual se materializou na fundação da Associação Brasileira de Educação (ABE), em 1924, e no Manifesto dos Pioneiros da Educação Nova, em 1932, no Rio de Janeiro. A partir de então, a pedagogia tradicional daria crescente espaço à pedagogia nova, que desembocaria na promulgação da Lei de Diretrizes e Bases da Educação Nacional de 1961 (grifos do autor).

Nesse contexto, a educação é organizada e regulada por normas legais rígidas, os traços da burocratização se apresentaram na escola de maneira acentuada. A organização da educação passa a ser baseava na perspectiva burocrática em que a racionalidade penetra na escola e influência o processo pedagógico. No processo educativo há uma grande predominância da administração burocrática presente na separação entre a concepção e a ação, o que deu origem às funções especializadas no seu interior, sendo alguns responsáveis em conceber teoricamente o ensino e outros em executar aulas. De maneira mais ampla Thurler (2001, p. 28) expõe a influência da lógica burocrática no processo educativo:

[...] a lógica burocrática é fortemente interiorizada pelos atores; ela influencia a maneira pela qual eles percebem seu papel seu estatuto, sua zona de autonomia, a divisão do trabalho, as relações de poder, a gestão dos processos da mudança, os mecanismos de controle. Na maioria dos casos, esse modo de organização foi de tal maneira absorvido que a mais forte tendência consiste em confundi-la com a escola: os atores não imaginam poder funcionar de outro modo, não percebem que a organização do trabalho existente é o resultado de uma construção social, com sua parte de arbitrário. (grifos da autora).

Percebe-se que a escola passou a orientar suas ações conforme a lógica burocrática, primando pela organização rígida baseada na normatização de ações. Há uma ênfase extrema na compartimentarização do saber e especializações das funções, fortifica-se a pedagogia pragmática, no intuito de oferecer soluções de natureza técnica para resolver os problemas educacionais. Os adeptos da organização burocrática acreditavam ser impossível pensar em outro modelo de organização, pois poderia acarretar conseqüências graves, comprometendo a qualidade do ensino. Nessa compreensão acreditava-se que pensar em organização estava diretamente relacionada com a concepção burocrática. Nessa perspectiva, desenvolve-se a corrente pragmática no intuito de solucionar os problemas da organização do ensino. Segundo Sander (2007, p. 29): 
[...] O pragmatismo trouxe para o campo da gestão da educação as potencialidades das doutrinas norte-americanas de William James (1909) e John Dewey (1916) para explicar o valor das orientações pedagógicas em termos de satisfação e utilidade prática. No entanto, é preciso destacar que o pragmatismo pedagógico teve que enfrentar a força da tradição do direito administrativo romano no Brasil, que continuou presente durante toda a fase organizacional e se estende até os dias de hoje.

Nesse sentido, transferem-se os mecanismos de divisão do trabalho das empresas para a organização da gestão da educação e da escola, em que os sujeitos e o ensino segue a lógica burocrática fundamentada em procedimentos rígidos por meio do controle dos processos de trabalho, particularmente do professor e tratamento padronizado no que concerne aos alunos. Houve um excessivo processo de hierarquização das funções no espaço escolar por meio da verticalização dos comandos, em que os donos dos cargos (representada pela equipe dirigente) impõem as tarefas educativas para legitimar as posições destes na atividade de mando. De acordo com Lück (2008, p. 88-89):

[...] Na medida em que há a acentuação da burocratização, ocorre acentuação da hierarquização, associada à criação de níveis de burocratas, cujas responsabilidades maiores se tornam as de atuarem como "zeladores" de normas e regulamentos estabelecidos e legitimam a sua posição e o seu trabalho. Hierarquia pressupõe um poder de influência unidirecional, de cima para baixo e de fora para dentro.

Nesse caso, o dirigente educacional na figura do diretor impõe as normas e regulamentos que devem orientar o processo de organização da escola e cabe ao professor e demais executálos. A escola torna-se permeada por forte hierarquização o que caracteriza a organização burocrática, sendo exercida por meio da racionalidade e impessoalidade da administração escolar. Essa racionalidade e impessoalidade eram tidas como possibilidade para resolver os problemas organizacionais e administrativos. Thurler $(2001$, p. 28$)$ confirma a hierarquização no processo de burocratização imposto à organização da escola:

[...] ele racionaliza o trabalho com base em procedimentos padronizados, decididos pelas autoridades ou prescritos por especialistas; permite aos professores concentrarem-se no trabalho pedagógico em classe, sem ter de se preocuparem com problemas administrativos; define de maneira clara e estável as tarefas de uns e de outros, o que permite eximir-se do reajustamento constante que seria exigido por uma análise aprofundada das relações entre as necessidades e os recursos. Protege a totalidade dos atores, definindo claramente as margens de manobra de cada um, o que coloca um freio nas tentativas de tomada de poder daqueles que não possuem autoridade formal; protege os direitos de uns e de outros e permite decidir em caso de conflito.

A partir desses comentários os arranjos formais prescritos na organização da escola promovem uma comodidade no desenvolvimento do trabalho pedagógico ao definir rigidamente as tarefas de cada sujeito dentro do processo educativo. $O$ controle desse processo não permite que os envolvidos tenham poder de decisão nas questões administrativas, pois os que detêm a autoridade formal definem as normas, cabendo aos demais segui-las rigorosamente. Desse modo, os conflitos necessários ao desenvolvimento do processo educativo são reprimidos, uma vez que 
existe um padrão de formalidade, em que os detentores dos cargos não permitem questionamentos das normas estabelecidas.

De um modo geral, mesmo reconhecendo a contribuição da administração pública burocrática na superação do patrimonialismo e na organização do Estado moderno, Pereira (2003) critica sua rigidez e ineficiência. Indicando-a como vítima do corporativismo dos funcionários públicos, assim pode-se considerar que a administração weberiana foi intensamente questionada por ser avessa a inovações, tendo em vista que houve intensas modificações devido ao desenvolvimento dos avanços científicos e tecnológicos, modificando as necessidades sociais, econômicas e políticas da sociedade. A concepção de dominação é própria, portanto, a toda ordem administrativa existente até os dias atuais. No entanto, a administração burocrática exerce a dominação de forma racional, subsidiada por parâmetros rigorosamente formal e legal. A definição de Weber de burocracia nos remete a uma forma racional de administração necessária para obter a obediência de um grupo de pessoas. Em suma, pode-se dizer que a burocracia é uma estrutura administrativa racional de dominação.

\section{CONSIDERAÇÕES FINAIS}

De modo mais amplo, a lentidão excessiva da burocracia, a ausência de sensibilidade para responder às novas e diversas demandas da sociedade, sua restrita cordialidade no atendimento ao público e o alto custo da administração estatal formavam uma nova frente de ataque ao Estado. Forma-se uma situação favorável à ideia de reformar com urgência o Estado. Uma de suas ideias mais polêmicas refere-se à adequação das concepções da burocracia weberiana, visto a sua incapacidade em responder às necessidades de um Estado ágil e eficiente no contexto da globalização econômica, que se inicia em meados dos anos de 1980. Nesse período, vivencia-se no mundo o processo de reestruturação produtiva (superação do modelo taylorista/fordista pelo flexível) e hegemonia do ideário neoliberal que exige outras possibilidades de organização da sociedade, bem como da escola. Desse modo, o modelo burocrático não atendia de maneira ampla as inovadoras necessidades sociais, bem com a organização da gestão da escola que nesta realidade deveria ser norteada pelos princípios de produtividade, eficiência e eficácia.

\section{REFERÊNCIA}

1. ABRUCIO, Fernando Luiz. O impacto do modelo gerencial na administração pública: um breve estudo sobre a experiência internacional recente. Cadernos ENAP, n 10, 1997.

2. CRUZ, Jane Alisson Westarb. A burocracia fora do senso comum. Rev. Perspec. Paraná/PR; Contemp. Campo Mourão, v.1, n.1, jan/jul., 2006.

3. LÜCK, Heloísa. Perspectiva da Gestão Escolar e Implicações quanto à Formação de seus Gestores. Em Aberto, Brasília, v. 17, n. 72, p. 11-33, fev/jun. 2000.

4. MATOS, Francisco Gomes de. Desburocratização. Rio de Janeiro: Biblioteca do Exército, 1979.

5. MOTTA, Fernando C. P.; PEREIRA, Luiz C. B. Introdução à organização burocrática. 4. ed. São Paulo: Brasiliense, 1984.

6. PEREIRA, Luis Carlos B. Gestão do setor público: estratégia e estrutura para um novo Estado. In: PEREIRA, Luis Carlos B.; SPINK, Peter (org.). Reforma do Estado e Administração Pública 
Gerencial. 5 ed. Rio de Janeiro: Ed. Fundação Getulio Vargas, 2003.

7. POULANTZAS, Nicos. O estado, o poder, o socialismo. São Paulo: Graal, 2000.

8. SANDER, Benno. Adminstração da Educação no Brasil: genealogia do conhecimento. Brasília: Liber Livro, 2007.

9. THURLER, Mônica Gather. Inovar no interior da escola. Porto Alegre: Artmed, 2001.

10. TRAGtenBerg, Maurício. Burocracia e ideologia. São Paulo: Ática, 1980.

11. WEBER, Marx. Economia e sociedade: fundamentos da sociologia compreensiva. Brasília: Ed. UnB, 1001 (Volume 1).

12. Ciência e Política: duas vocações. São Paulo: Cultrix, 1970. 